\title{
THE STRUCTURE AND FUNCTION OF THE TUBE FEET IN CERTAIN ECHINODERMS
}

\author{
By J. E. Smith, Ph.D. \\ Department of Zoology, University, Sheffield
}

(Text-figs. I-8)

CONTENTS

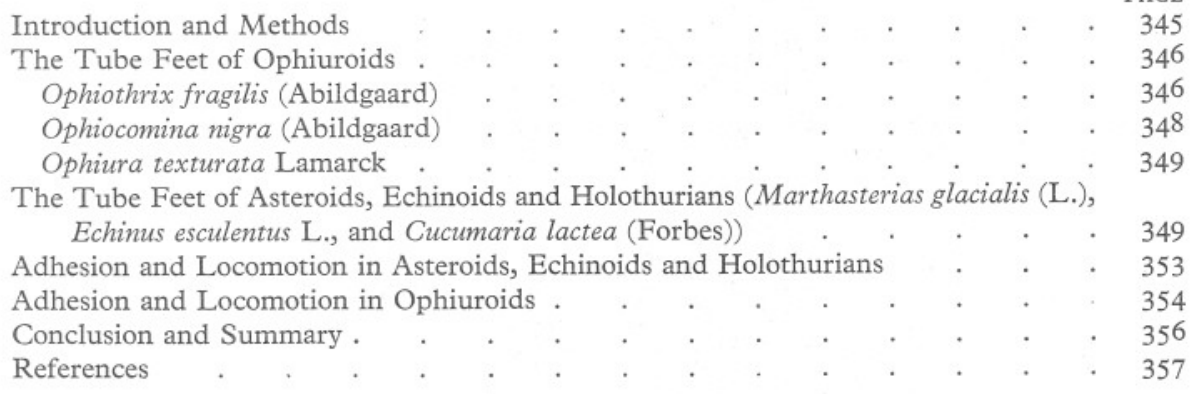

\section{INTRODUCTION AND METHODS}

It is well known that the suckers of the tube feet of asteroids, echinoids and holothurians serve as organs of adhesion, and that where the sucker is but poorly developed, as, for example, in Astropecten, which burrows in sand, adhesion is of secondary importance only. Paine (I926) has analysed the process of adhesion in the starfish Asterias vulgaris-a form with well-developed suckers-and concludes that adhesion is due in part to suction but "that some other factor, very probably stickiness", must also be considered.

In order to determine to what extent mucus glands may be regarded as providing means of adhesion in the Eleutherozoa as a whole, observations have been made on the tube feet of Marthasterias glacialis, Echinus esculentus, Cucumaria lactea, and three ophiuroids which are of common occurrence around the coasts of Britain, namely, Ophiothrix fragilis, Ophiocomina nigra and Ophiura texturata. Observations on living animals were made at various times during the years 1936 and 1937 in the Laboratory of the Marine Biological Association at Plymouth. Material for sectioning has been fixed in Heidenhain's "Susa" fixative in sea water, with subsequent decalcification in a $3 \%$ mixture of nitric acid in $70 \%$ alcohol. Sections cut $6 \mu$ thick were stained with Mallory's triple stain, Heidenhain's iron-alum haematoxylin, Delafield's haematoxylin and eosin, Giemsa, Mayer's mucicarmine and muchaematein. 
I am indebted to the University of Sheffield for the use of their table at the Plymouth Laboratory and to the Director and Staff of the Laboratory for the assistance which they have afforded me during my occupation of the table.

\section{The Tube Feet of Ophiuroids}

Ophiothrix fragilis (Abildgaard).

The tube feet of an active Ophiothrix fragilis are maintained in a state of extension. They are long and mobile and of a length slightly greater than the width of the arm. When the animal is moving over a horizontal surface the feet

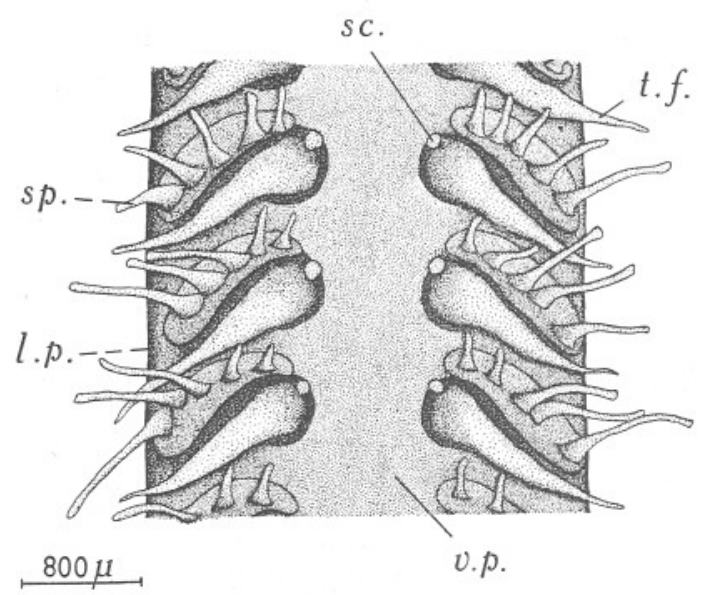

Fig. I. A part of the oral surface of an arm of Ophiothrix fragilis. l.p., lateral arm plate; $s c$., tentacle scale; $s p$., arm spine; $t . f$., tube foot; v.p., ventral arm plate.

are held out laterally, and frequently bend dorsally so as to arch over towards the aboral side of the arm. In so doing they provide, as far as it is possible to observe, the only means of contact with the substratum.

Fig. I is a view of the under surface of a part of an Ophiothrix arm. The tube feet (t.f.) emerge through openings between the ventral (v.p.) and lateral arm plates (l.p.), and each is covered, proximally, by a tentacle scale (sc.) which, however, is minute and in no way impedes the movement of the podium.

Fig. $5 a$ represents, diagrammatically, a longitudinal section through the protruded portion of the tube foot. The epithelium $(e$.$) is thrown into broad-$ based conical folds or "papillae" $(p$.$) and is everywhere covered by a thin$ cuticle not exceeding $\mathrm{I} \mu$ in thickness. Below the epithelium there is a neurofibrillar plexus (n.f.), and below this again, in order, are layers of connective tissue (c.t.), longitudinal unstriped muscle fibres (l.m.) and coelomic epithelial cells (c.e.), the latter frequently, in fixed podia, completely obliterating the coelomic cavity. The connective tissue layer is not wholly internal to the sub- 
epithelial nerve plexus but lies, in part, external to it, a condition which is peculiar to Ophiothrix and is not to be found either in the Asteroidea, Echinoidea or in the other two ophiuroids studied. The podium tapers, distally, to a point, there being no trace of a sucker.

Examination of a papilla shows that it is crowded with elements which stain readily with acid fuchsin and Giemsa, rather less so with Delafield's haematoxylin and Heidenhain's iron-alum haematoxylin. Hamann (I889), in his excellent account of the nervous system of $O$. fragilis, described these papillae as sense buds and the deeply staining elements as sense cells. Each of these so-called sensory cells has a peripheral projection (Stäbchen), an elongate cell body with a nucleus and a nerve fibril directed into the subepithelial neuro-

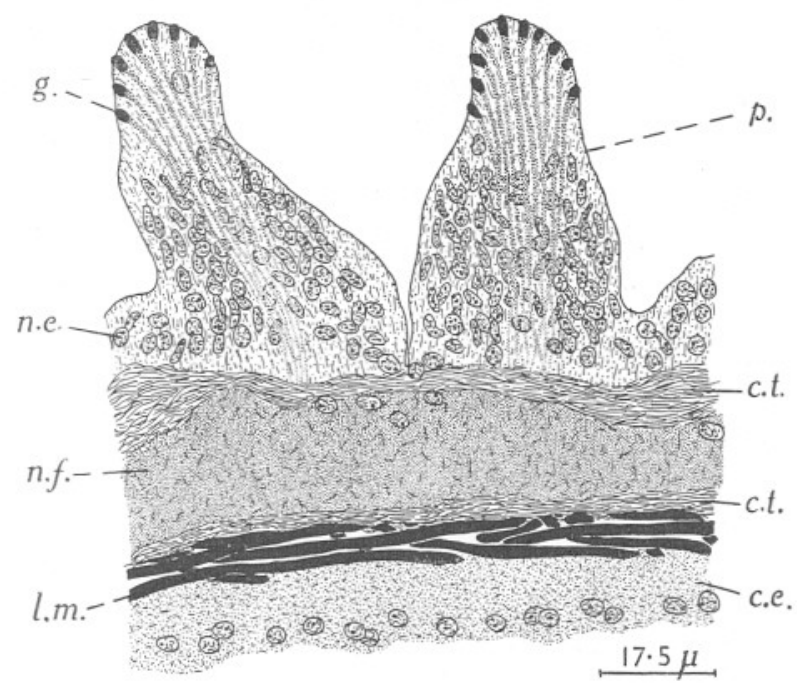

Fig. 2. A part of the wall of a tube foot of Ophiothrix fragilis, showing two papillae with the glandular elements. c.e., coelomic epithelium; c.t. connective tissue; g., gland; l.m., longitudinal muscle fibre; n.e., nucleus of epithelial cell; $n$. $f$., neurofibrillar plexus; $p$., papilla.

fibrillar plexus. Hamann is in error in his conception of the papillae as being exclusively sensory. Sensory elements there certainly are within the papilla, but the elements he described are glandular and not nervous in function.

Fig. 2 shows two adjacent papillae in more detail. The glands $(g$.) are long and narrow, attaining to a length of $50-60 \mu$, but of greatest width not exceeding $2 \mu$. The base of the gland is narrower than its distal extremity and rests on the connective tissue (c.t.) external to the neurofibrillar plexus (n.f.). The long axes of the glandular elements are directed along the length of the papilla $(p$.$) and either continue on this course to open terminally on the papilla$ or bend slightly outwards to have a subterminal opening. In sections of tube feet which have been stained with Delafield's haematoxylin or with Heidenhain's iron-alum haematoxylin, the glands are stained but feebly. In this 
condition they take on a uniform blue or dark grey colour and might easily be mistaken for sensory elements, but with Mallory's triple stain or with Giemsa a totally different picture is obtained. The greater part of the gland is filled with small droplets which give to it a granular appearance. The droplets situated near the base of the cell are only slightly tinged, but the colour is intensified towards the middle region. Distally, the droplets react even more readily with the stain and at the extreme tip of the gland they merge together, the whole of the tip thus being filled with a brightly staining fluid. The tip projects slightly beyond the limit of the ectoderm and apparently penetrates the thin cuticle to open on its outer surface. The nucleus of the gland cell is not distinguishable from the nuclei of the epithelial cells (n.e.), but in most instances appears to be applied to the middle of the gland. The papillar glands of Ophiothrix with their content of secretion droplets recall the "Körnchendrüsenzellen" of asteroids (Smith, I937), but the goblet cells which occur in the latter group appear to be absent from the ectoderm of Ophiothrix. The goblet cells of asteroids are mucus cells, but the "Körnchendrüsenzellen" are not usually regarded as mucus secreting. In the absence of other types of glands, in the ophiuroid, one must naturally suppose that the papillar glands function as mucus cells. With Mayer's mucicarmine the glandular elements tinge only very faintly pink, but they react more readily with muchaematein. An attempt was made to test for mucus by permitting active Ophiothrix to walk over cover-slips which were then placed in Heidenhain's "Susa" fixative, washed and stained with mucicarmine and muchaematein. The results were entirely negative. Similar tests with Ophiocomina, however, showed the presence of slight traces of mucus, and when the animal was allowed to crawl up a vertical glass surface distinct tracts of mucus were to be seen where the feet had adhered to the glass. As the glands in the tube foot of Ophiocomina present a precisely similar appearance to those of Ophiothrix we may assume that both are mucus secreting.

Ophiocomina nigra (Abildgaard).

The tube feet of this ophiuroid are capable of considerable extension. When the animal is moving they are in constant motion and are never bent over the aboral surface in the manner characteristic of Ophiothrix. The podia emerge in pairs from apertures situated lateral to the ventral arm plates (Fig. 3, t.f., v.p.), the apertures being partly covered, proximally, by two tentacle scales (sc.). The feet are papillated, though not so obviously as are the podia of Ophiothrix. The distal end of the tube foot does not taper to a point but ends in a blunt knob, rather like a rudimentary sucker (Fig. $5 b, k$.). In the arrangement of the layers of its wall the podium differs but little from that of Ophiothrix; the subepithelial plexus is, however, entirely external to the connective tissue layer. The glandular elements are histologically similar to those of Ophiothrix and have the same staining reactions. As in the latter type, the glands are restricted to the papillar areas, but in Ophiocomina nigra the 
terminal knob, which is not represented in the Ophiothrix podium, is also plentifully supplied with glands which, on account of the relatively great depth of the ectoderm in this region, are correspondingly elongate, their basal ends resting against the connective tissue.

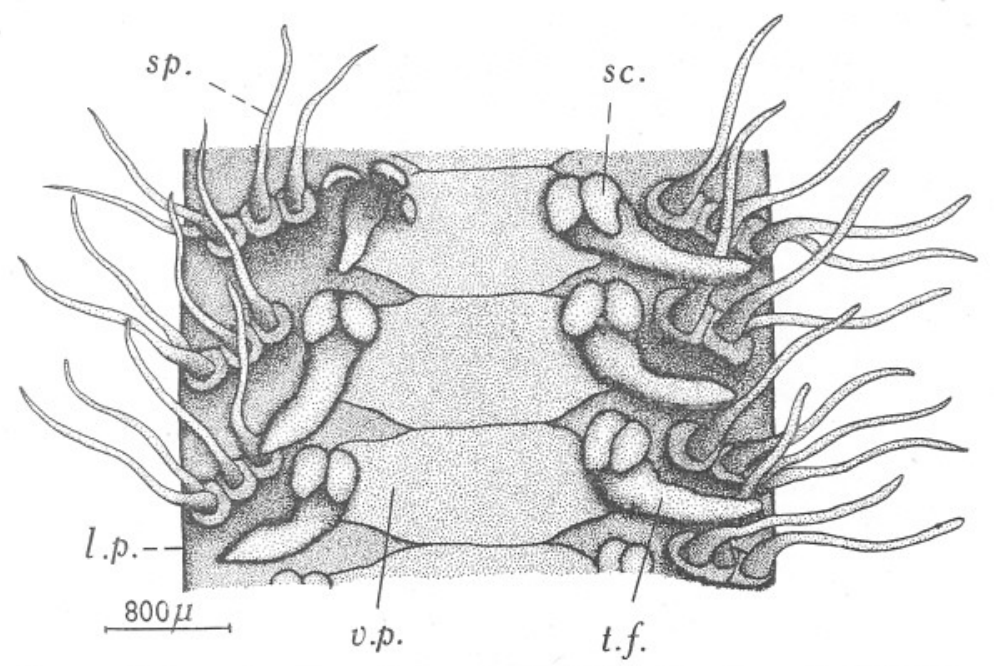

Fig. 3. A part of the oral surface of an arm of Ophiocomina nigra. l.p., lateral arm plate; sc., tentacle scale; $s p$., arm spine; t.f., tube foot; v.p., ventral arm plate.

Ophiura texturata Lamarck.

In shape the tube feet of this species (Figs. 4, 5c) are of an intermediate type between those of Ophiothrix and Ophiocomina. The distal end of the foot is neither drawn out into a point nor does it constitute anything akin to a sucker. The diagrammatic figure of a longitudinal section through an Ophiura tube foot (Fig. $5 \mathrm{c}$ ) is of a contracted fixed specimen. In life, the papillary areas are not well marked although the glands $(g$.$) , similar to those already described,$ are restricted in distribution to the rather ill-defined elevations of the ectoderm. These glandular elements are fewer in number than in Ophiothrix or Ophiocomina. The tentacle scales (Fig. $4, s c$.) which cover the base of the tube feet are large and numerous, and the podia, which are directed towards the tip of the arm while at rest, are not capable of the same degree of extension as are the tube feet of the other two ophiuroids.

\section{The tUBE FeET of Asteroids, EchinoIds AND Holothurians}

(Marthasterias glacialis (L.), Echinus esculentus L., and Cucumaria lactea (Forbes).)

These three classes of the Echinodermata all contain members which have tube feet provided with well-developed suckers. Where the tube feet or suckers are absent the condition is undoubtedly a secondary one. Examination of the 
$s c$. v.p.

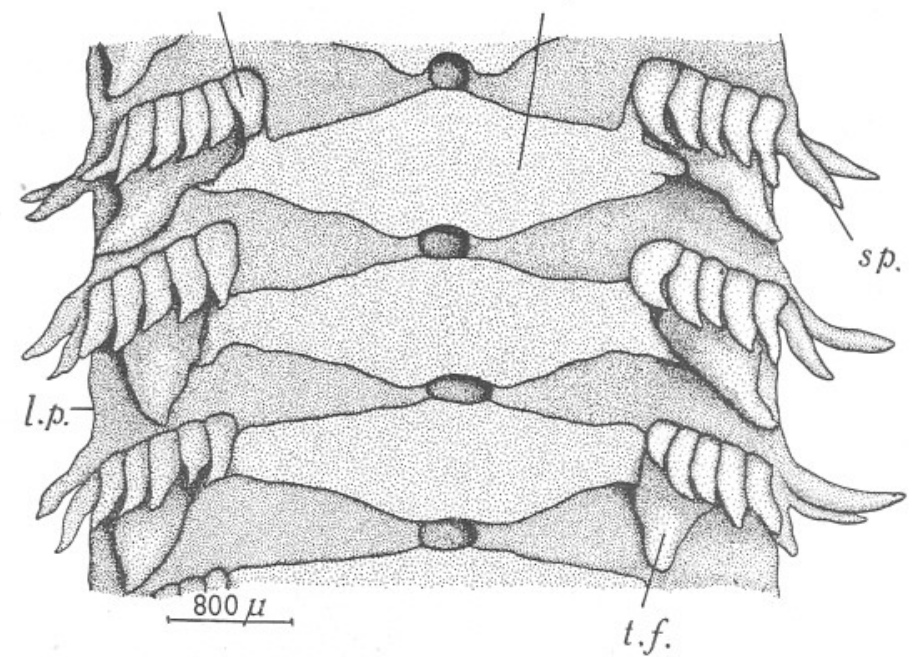

Fig. 4. A part of the oral surface of an arm of Ophiura texturata. l.p., lateral arm plate; $s c$. , tentacle scale; $s p$., arm spine; $t . f$., tube foot; v.p., ventral arm plate.

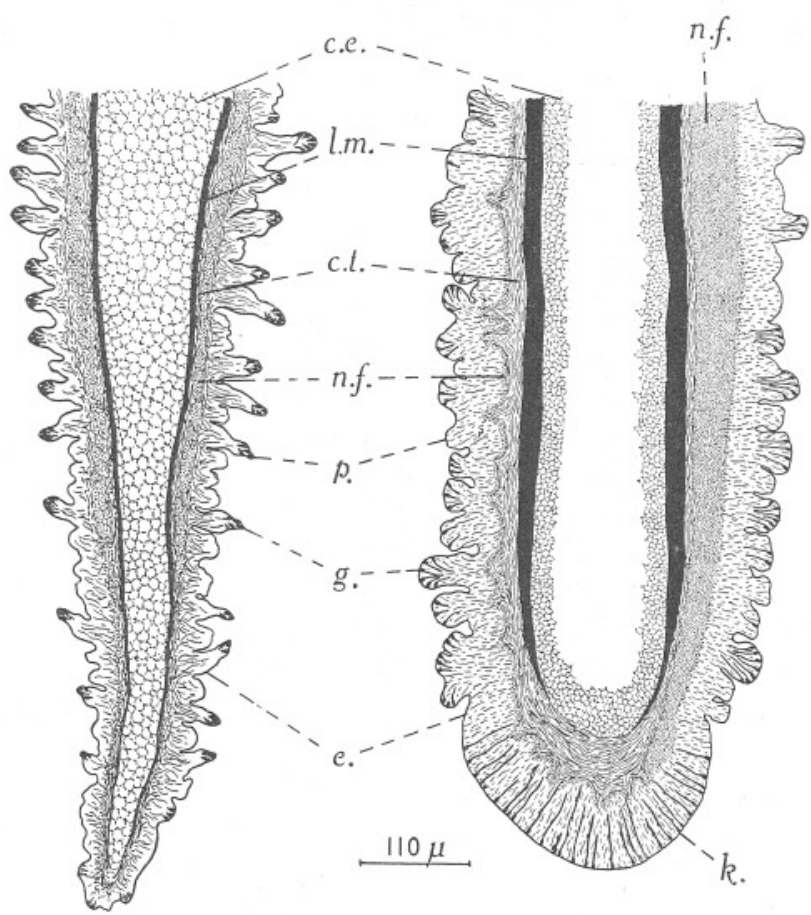

a

$b$

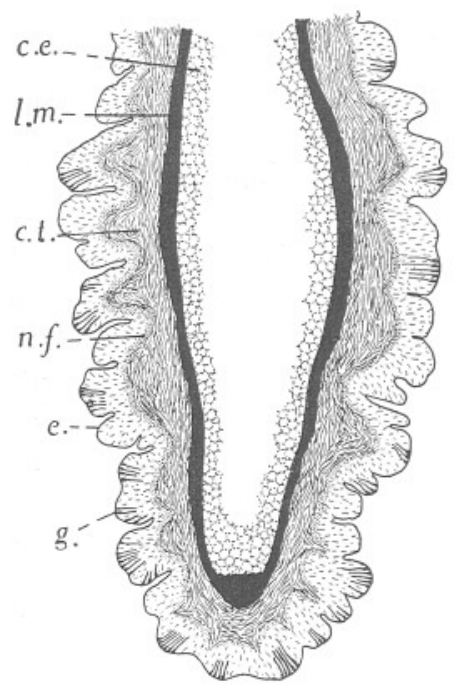

Fig. 5. Diagrammatic longitudinal sections of tube feet of $a$, Ophiothrix fragilis, $b$, Ophiocomina nigra and c, Ophiura texturata; the cuticle is omitted. c.e., coelomic epithelium; c.t., connective tissue; $e$., epithelium; $g$. , gland; $k$., terminal knob of the tube foot; l.m., longitudinal musculature; $n . f$., neurofibrillar plexus; $p$., papilla. 
feet of three typical members, namely, Echinus esculentus, Marthasterias glacialis and Cucumaria lactea, reveals an essential similarity of form of the sucker throughout the three classes. The type may be exemplified by consideration of an ambulacral tube foot of Echinus esculentus. The arrangement of the tissues in an Echinus podium is shown in Fig. 6. The outer part of the wall is constituted by a thick epidermis made up, for the most part, of ciliated epithelial cells $(e$. ) covered by a thin cuticle but containing, in addition, sen-

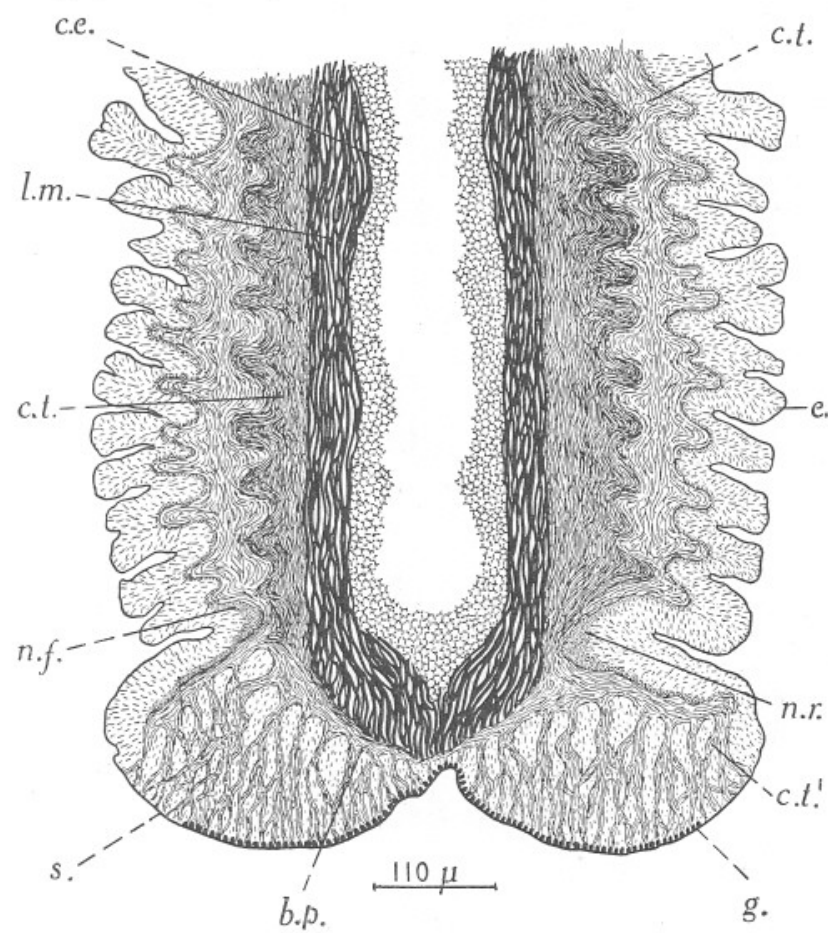

Fig. 6. A diagrammatic longitudinal section through the distal part of a tube foot of Echinus esculentus - the cuticle is omitted. b.p., basal plate of connective tissue; c.e., coelomic epithelium; c.t., connective tissue; c.t.', arborescent system of connective tissue fibres in the disk; $e$. ., epithelium; g., elongate gland of the sucker; l.m., longitudinal musculature; $n . f$., neurofibrillar plexus; n.r., nerve ring; s., sucker.

sory elements and, in the sucker only, glandular cells $(g$.) to which reference will later be made. Underlying the epithelium is a plexus of nerve fibrils (n.f.) which, at the base of the sucker, forms a nerve ring (n.r.). The connective tissue (c.t.) consists of coarse wavy strands of tissue and is sharply demarcated into two layers, the inner being the more dense. Internal to the connective tissue are the longitudinal muscle fibres (l.m.) and the cells of the coelomic epithelium (c.e.), the latter bordering the cavity of the foot. The tube feet of Echinus contain spicules which are lodged in the connective tissue layer and which, in the basal plate of connective tissue, form a calcareous plate. 
The sucker itself is of a complex structure. From the distal surface of the basal plate there radiate numerous arborescent connective tissue septa. The branches of the septa (Fig. 6, c.t.') become finer and finer the nearer they approach the surface of the ectoderm, so that the epithelium is penetrated by a number of fine connective tissue strands all of which have their origin in the basal plate (b.p.). Epithelial and glandular elements are intruded between the strands. The glandular cells $(g$. $)$ are confined absolutely to the contact surface of the sucker, and in this region, as Fig. 6 shows, they displace the epithelial

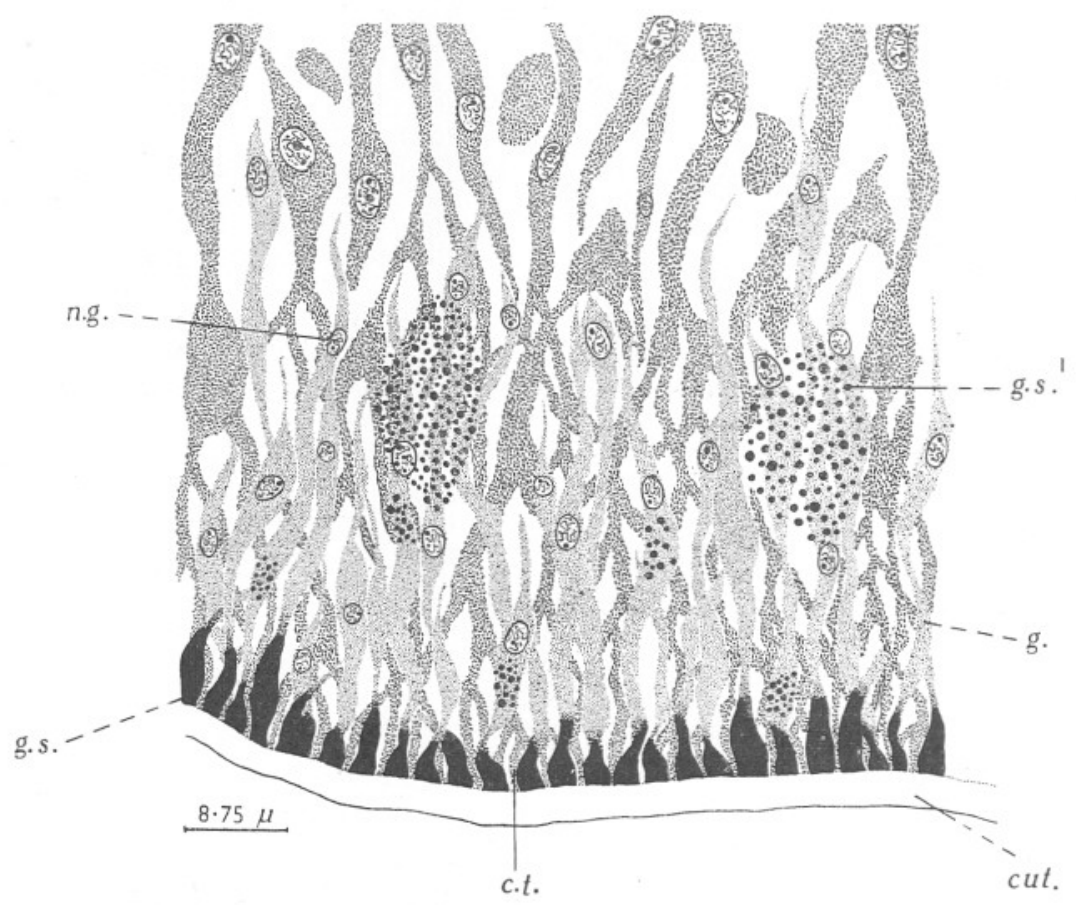

Fig. 7. A part of the wall of the tube foot sucker of Echinus esculentus. c.t., connective tissue fibre; cut., cuticle; g., elongate gland of the sucker; g.s., glandular secretion in distal part of gland; g.s.', glandular secretion in proximal part of gland; $n . g$., nucleus of glandular element.

cell entirely. The epithelial and glandular cells which are similar in form are long and narrow, not exceeding $5 \mu$ in width but attaining a length of $50 \mu$ or more. After fixation with Heidenhain's "Susa" mixture the cytoplasm of the cell has a finely granular appearance. The rounded or oval vesicular nucleus (Fig. $7, n . g$.), of about $2.5 \mu$ diameter, is usually centrally placed but may be found towards the proximal or distal end of the cell. The glandular elements differ from the epithelial cells in their ability to secrete a fluid which stains readily with acid fuchsin and muchaematein and to a lesser extent with Heidenhain's iron-alum haematoxylin, Delafield's haematoxylin and Mayer's 
mucicarmine. Each cell has a deeply staining distal portion (Fig. 7, g.s.) in which the secretion consists either of numerous closely apposed droplets or of a homogeneous fluid mass formed, presumably, by the flowing together of the originally separate droplets. The greater part of the gland is devoid of secretion, but, here and there, larger masses of droplets, representative of secretory activity in adjacent cells, are to be found (Fig. 7 , g.s.').

The tube-foot sucker of Marthasterias glacialis is very similar in form to that of Echinus. There is the same arrangement of the arborescent connective tissue and of the glandular elements; these latter are of the "Körnchendrüsenzell " type, rather longer and wider than those of Echinus, but occupying a similar position on the contact surface of the sucker. In Marthasterias it is noticeable that the glands are not confined to the sucker but are also found throughout the remainder of the tube-foot ectoderm. In this latter position, however, they are smaller, more rounded, and resemble the glands which have been described as occurring in the radial nerve cord and elsewhere (Smith, 1937).

Material for the study of the holothurian tube foot has been rather limited, and it has not been possible to determine the form of the glandular elements with any degree of certainty. It is clear, however, from the few sections of Cucumaria available that the deeply staining portions of the gland are terminal in position and are, as in the asteroid and echinoid, restricted to the contact surface of the tube foot. Here, as in the two latter groups, the connective tissue, with its origin in the basal plate, penetrates the ectoderm of the sucker, the finer branches terminating at the surface of the epithelium under the cuticle.

\section{AdHeSion AND Locomotion in Asteroids, EchinoIds AND HOLOTHURIANS}

Reference has been made earlier in this paper to the observations of Paine (1926) on the adhesion of the tube feet of the starfish Asterias vulgaris. This author concluded that the average adhesive force of a single podium was approximately $\mathrm{I} 8 \mathrm{~g}$. per $\mathrm{mm} .{ }^{2}$ of contact surface and that of this, approximately $56 \%$ was due to suction, the remainder being due to some other factor, probably stickiness.

When a starfish applies a tube-foot sucker to the substratum, complete contact with the latter is effected by an inflow of fluid from the ampulla into the cavity of the podium. The basal plate is then pulled backward, a vacuum remaining between the central part of the disk and the surface of contact. The backward pull is effected by contraction of the longitudinal musculature, and the pull is in some way transmitted to the epithelial surface of the sucker. One cannot but conclude that the system of radiating connective tissue fibres, which is of such constant occurrence in the suckers of the tube feet of asteroids, echinoids and holothurians, is an adaptation for the transmission of the back- 
ward pull to all parts of the disk and serves for the rapid and effective establishment of the vacuum responsible for suction. This view is supported by the fact that in the ophiuroids, where there is no marked adherence by suction, the system of arborescent connective tissue fibres is lacking.

The other constant feature of the tube-foot sucker, within the three groups under consideration, is the restriction of the elongate glandular elements to the contact surface. Locomotion in an asteroid, echinoid or holothurian demands the repeated application of the sucker to the substratum, and with each application a small quantity of mucus is required to be secreted in order to provide the stickiness which reinforces the action of suction. Paine (1926) found that it was impossible to exhaust this secretion either by repeated application of the tube foot to the substratum or by treatment with chemicals. In explanation of this condition the extreme length of the glands in the region of the sucker is a factor which ought not to be ignored, for it is obvious that these glands have a mucus content much greater than that of the much smaller, more globular, glands of the rest of the ectoderm. In short we find, in the sucker of asteroid, echinoid or holothurian podia, a perfect mechanism for the exploitation of suction and of adhesion by secretion of mucus, both of which, as Paine has shown, are of almost equal importance in the attachment of the foot. For the effective production of the vacuum necessary for suction there is the longitudinal musculature acting through the connective tissue fibres, and for continuous mucus secretion there are mucus glands so constructed as to supply secretion over a long period.

\section{ADHESION AND LOCOMOTION IN OpHIUROIDS}

Movement of an ophiuroid over a horizontal surface is effected, primarily, by sinuous movements of the arms. When the animal is advancing in a given direction it does so either with one arm directed along the line of advance or with an interradius leading. In the former case the arms adjacent to the leading one, by flexing, move the animal in a series of jerks, while in the latter instance the two pairs of arms on either side of the leading interradius are responsible for progression. It would appear, from a cursory examination, that the tube feet play no part in the progressive movement, and this was the view held by earlier workers such as Preyer (I886-7) and Hamann (I90I). Brooks and Grave (I899), however, showed that in Ophiura brevispina the tube feet adapt themselves to irregularities of the surface and form the points on which the arms are drawn. Östergren (1904), Cowles (I910) and May (I925) corroborate this statement, and May further shows that in Ophionereis reticulata the tube feet are able to attach themselves to the substratum even when the latter is perfectly smooth. The tube feet are in complete extension along the length of the arm, the weight of which is thrown on a particular set of podia. The distal part of each affected foot bends at right angles to the rest of the podium and so forms a small pad on which the arm is levered forward. 
Östergren's (1904) observations on Ophiocomina nigra indicate that this animal adopts a similar method of progression although no crooking of the podium is to be noted.

I have been able to study the movement of Ophiocomina in aquaria and in large glass dishes where the tube feet could be observed during the traverse of either a horizontal or of a vertical surface. Active specimens of Ophiocomina use, not one, but two methods of progression. The first is the quick movement dependent on flexure of the arms, such as Östergren described, and which is effected by the tube feet acting as a fulcrum on which the arm is pivoted, but the second method is strikingly similar to that adopted by an asteroid, and appears to be used chiefly in the climbing of vertical surfaces.
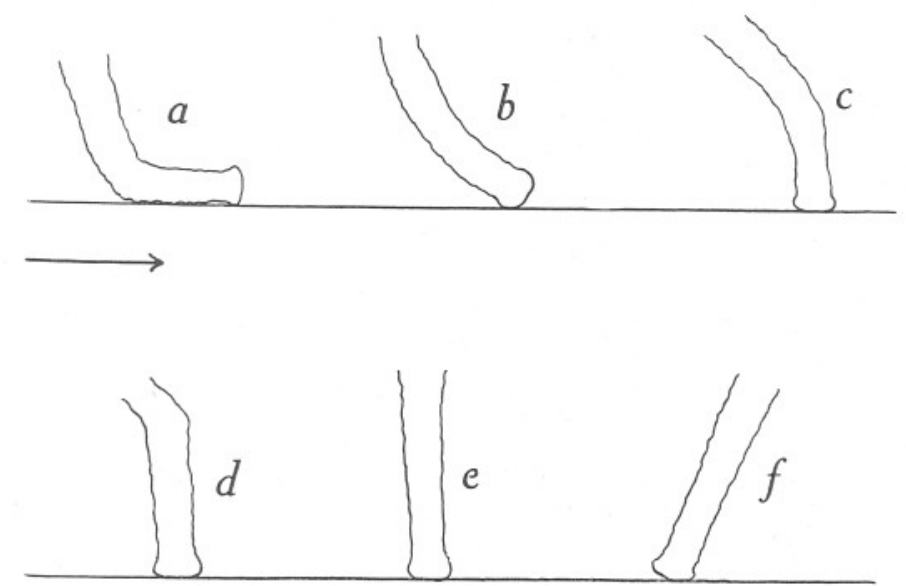

Fig. 8. The successive phases of movement $(a-f)$ of the tube foot of Ophiocomina nigra in the climbing of a vertical surface.

When the animal starts to climb a vertical surface it pushes itself up by the disk and by the arms remaining on the horizontal substratum, the vertical progression being assisted by the movement, both by flexing and gliding, of the arms already established on the vertical surface. Once the animal has left the horizontal surface, however, the movement is entirely of a gliding nature for which the podia, alone, are responsible. The arms remain perfectly rigid, while the tube feet of all the arms move actively in a plane corresponding to the line of advance of the animal. In so doing the podia pass through the successive phases of movement indicated in Fig. 8, though not all the tube feet are in the same phase at the same moment. The tube foot stretches forward and applies the side of the sucker and the distal third of the side of the podium to the surface of the glass (Fig. 8 a). The terminal knob then turns so that only its tip adheres to the glass, the distal part of the podium becoming bent at an angle to the rest of the foot (Fig. $8 \mathrm{c}$ ). The foot now straightens out in the manner indicated (Fig. $8 d$ ) until it is entirely vertical (Fig. $8 e$ ). While the foot 
remains in this taut condition the animal moves forward slightly and comes to lean back at an angle to the surface (Fig. $8 f$ ). At this point the knob is detached with a jerk-itself indicative of former attachment-and the tube foot is stretched forward again for a re-application to the surface of the glass. If the animal be disturbed in its climb, all the feet detach themselves simultaneously and the animal falls to the bottom of the dish soon, however, to recommence its upward climb.

Although specimens of Ophiothrix have been kept in glass dishes for several hours at a time they have not been induced to climb up the sides of the vessels. It may be that the tube feet are unable to hold fast to such a smooth surface, for in aquaria the animals maintain themselves on the vertical walls by bending their arms round the irregularities of the surface or by pressing themselves into the corners of the tank. Ophiothrix will hold themselves on to a vertical wall merely by the attachment of their podia, but the adhesive process is not so effective as in Ophiocomina. Adhesion is here effected by the application of the greater part of the sides of the tube feet to the substratum, the podia being held at right angles to the long axis of the arm, in which position the papillae, with the mucus glands at their tips, are able to maintain contact.

\section{CONCLUSION AND SUMMARY}

Comparison of the methods of adhesion and locomotion of the typical members of the four classes of the Eleutherozoa reveals a similarity of the adhesive mechanism in the Asteroidea, Echinoidea and Holothuroidea in that adhesion is due in part to suction and in part to the secretion of mucus. The ophiuroid, on the other hand, has tube feet which, because of their lack of a well-defined sucker, must adhere merely by their intrinsic stickiness. The ability to make use of suction results from the possession of a sucker so fashioned that the median part of the disk may be withdrawn from the surface of contact, with the resultant production of a vacuum. The sucker of the asteroid, echinoid or holothurian tube foot is well adapted for this purpose. An essential feature of such a disk is the presence of an arborescent system of connective tissue fibres extending from the basal plate to the outer limit of the ectoderm. By means of this system, the pull initiated by contraction of the longitudinal musculature of the podium is transmitted to the ectoderm of the sucking disk, the central part of which is thereby lifted up. Where suction plays no part in adhesion, as in the Ophiuroidea, the arborescent system of fibres is lacking.

The ability to secrete mucus is an important subsidiary factor in the adhesion of the asteroid podium and may probably be of equal importance in the echinoid and holothurian, although the method of attachment in these latter two groups has not been analysed. Locomotion demands continued reapplication of the tube-foot disk to the substratum; accordingly, we find, in the three classes mentioned, that especially elongate mucus glands are present and that these are confined to the adhesive surface of the sucker. In Ophiothrix 
and probably most of the ophiuroids, however, it is the side of the tube foot which is pressed against the substratum; in this instance the mucus glands are distributed over the sides of the podium and are confined to the surfaces of contact, namely, the papillae.

Finally, it may be noted that Ophiocomina nigra resembles, in some degree, the asteroid, echinoid and holothurian in that its tube feet are furnished with rudimentary suckers. The terminal knob is well provided with glandular elements, and, although it may not adhere by suction, its sticky secretion enables the animal to perform walking movements and to maintain its position both on horizontal and on vertical surfaces.

\section{REFERENCES}

Brooks, W. K. and Grave, C., I899. Ophiura brevispina. Mem. Nat. Acad. Sci Washington, Vol. 8, 4th memoir, pp. 79-100.

Cowles, R. P., I9Io. Stimuli produced by light and by contact with solid walls as factors in the behaviour of Ophiuroids. Fourn. Exp. Zool., Vol. 9, No. 2, pp. 386$4 \mathrm{I} 6$.

Hamann, O., I889. Die Anatomie und Histologie der Ophiuren und Crinoiden. Beiträge zur Histologie der Echinodermen. Jena.

Hamann, O., I901. Bronn's Klassen und Ordnungen des Thier-reichs. Bd. 2, Abt. 3.

MAY, R. M., I925. Les réactions sensorielles d'une Ophiure (Ophionereis reticulata). Bull. Biol. France et Belge, T. 50, pp. 372-402.

Östergren, H., I904. Über die Funktion der Füsschen bei der Schlangensternen. Biol. Centralbl., Bd. 24, pp. 559-65.

PaIne, V. L., I926. Adhesion of the tube feet in starfishes. Fourn. Exp. Zool., Vol. 45, pp. $36 \mathrm{I}-6$.

PreYer, W., I886-7. Über die Bewegungen der Seesterne. Mitt. Zool. Stat. Neapel., Bd. 7, pp. 27-I27.

SMith, J. E., I937. On the nervous system of the starfish Marthasterias glacialis (L.). Phil. Trans. Roy. Soc., Ser. B, Vol. 227, pp. III-73. 